\title{
Acute Erythroleukemia in a Trauma Patient. A Case Report
}

\author{
Eriselda Taulla*
}

Received: 17 May 2020 / Accepted: 5 June 2020 / Published online: 20 January 2021

(C) The Author(s) 2021. This article is published with open access at https://journal.astes.org.al

\begin{abstract}
Introduction: Acute erythroid leukemia (AEL) is a rare type of acute myeloblastic leukemia. Acute erythroid leukemia is characterized by a predominant erythroid proliferation, there are 2 subtypes: erythroleukemia (erythroid/myeloid leukemia) and pure erythroid leukemia...

Myelodysplastic syndromes (MDS) are a group of biologically and clinically heterogeneous clonal disorders characterized by ineffective hematopoiesis and peripheral cytopenia due to high apoptosis

The purpose to presenting this case is how to differentiate an acute erythroleukemia (AEL) from myelodysplastic syndrome (MDS).

Case report. A 74 year old man came to emergency room after he falling down from the stairs and then was hospitalized with a two weeks history of severe weakness, anorexia, weight loss. He suffered of diabetes mellitus type II insulin dependent, and HTA. The physical examination showed cutaneous and conjunctival pallor, large ecchymosis in the low extremities and hepatosplenomegaly. CBC showed: pancytopenia and macrocytosis, neutrophils $60 \%$, normoblasts $4: 100$ and reticulocyte count $3 \%$.

Conclusions: The diagnosis was Acute Erythroid Leukemia. The \% of myeloblasts in bone marrow was $>20 \%$ of non-erythroid cells. Erythroleukemia characterizes from hepatomegaly this is found and in our case. Differential diagnosis is based mainly in bone marrow aspiration, immunophenotyping (flow cytometry)

Keywords: acute erythroleukemia, myelodysplastic syndrome, erythroblast
\end{abstract}

\section{Introduction:}

Acute erythroid leukemia (AEL) is a rare type of acute myeloblastic leukemia. Acute erythroid leukemia is characterized by a predominant erythroid proliferation, and in the current World Health Organization (WHO) classification scheme there are 2 subtypes: erythroleukemia (erythroid/ myeloid leukemia) and pure erythroid leukemia. Morphologic findings are most important for establishing the diagnosis. The erythroleukemia subtype, which is most common, is defined as the presence of $50 \%$ or more erythroid

Original article, no submission or publication in advance or in parallel

* Corresponding author:

Eriselda TAULLA MD

$\triangle$ eriseldarevizhda@gmail.com

Department of Internal Medicine, " University Hospital of Trauma”, Tirana, ALBANIA. precursors and $20 \%$ or more blasts in the nonerythroid component. The pure erythroid leukemia subtype is composed of $80 \%$ or more immature erythroblasts. It accounts for less than $5 \%$ of cases of acute myeloblastic leukemia. Usually occurs in patients 50 years of age or older. It is characterized by a prominent component of erythroblast.

The term leukemia is used for the first time in 1847 from Virchow. In 1857 Friedreich recognized acutae and chronic types. Di Guliemo described acute erythroleukemia in 1917.

Erythroleukemia is subtype of acute myeloblastic leukemia LAM6 according to French-American-British (FAB) classification.

As all hematologic malignancies the etiology for AEL and MDS is unclear but some risk factors are: prior chemotherapy (particularly alkylating agents and epipodophyllotoxins), ionizing radiation, benzene exposure, constitutional chromosomal abnormalities and smoking.

\section{Case Report:}

A 74-year-old man came to emergency room after he falling down from the stairs and then was hospitalized with a two 
weeks history of severe weakness, anorexia, weight loss. He suffered of diabetes mellitus type II insulin dependent, and HTA. The physical examination showed cutaneous and conjunctival pallor, large ecchymosis in the low extremities and hepatosplenomegaly.

CBC showed: pancytopenia and macrocytosis, neutrophils $60 \%$, normoblasts $4: 100$ and reticulocyte count $3 \%$. Serum B12-1225pg/ml and folates $-21 \mathrm{ng} / \mathrm{ml}$. DTC negative, ITC negative, LDH $1660 \mathrm{U} / \mathrm{L}$, total bilirubin 1,1 mg/dl, total proteins 5,6 g/dl, glucose $388 \mathrm{mg} / \mathrm{dl}$, and other parameters within the normal range. The bone marrow aspiration revealed: myeloblasts $6 \%$, promyelocytes $1 \%$, myelocytes $6 \%$, metamyelocytes $6 \%$, bands $5 \%$, neutrophils $4 \%$, proerythroblasts $4 \%$, basophilic normoblasts $4 \%$, polychromatophilic normoblasts $4 \%$, promegaloblasts $7 \%$, basophilic megaloblasts $10 \%$, polychromatophilic megaloblasts $36 \%$, orthochromatic megaloblasts $7 \%$. The rate myeloid/ erythroid $=1 / 3$, showing the predomination of the erythroid line which constitute $65 \%$ of all cells. The proportion of proerythroblasts and basophilic erythroblasts was 38\% of all erythroblastic cells. The proportion of megaloblastic forms was $80 \%$ of all erythroblasts. PAS staining of bone marrow smears showed typical cytoplasmatic positivity of pathologic erythroblasts: granular in more immature cells and diffuse in more mature ones, confirming the diagnosis of erythroleukemia.

We treat him with Cytarabine $100 \mathrm{mg} / \mathrm{m}^{2}$ every $12 \mathrm{~h}$ day1-7. The patient had an extremely aggressive clinical deterioration and he died ten days after admission.

\section{Discussion:}

Acute erythroid leukemia (AEL) is a rare type of acute myeloblastic leukemia. AML 6 according to FAB classification. There are 2 subtypes: erythroleukemia (erythroid/myeloid leukemia) and pure erythroid leukemia. Morphologic findings are most important for establishing the diagnosis. The erythroleukemia subtype, which is most common, is defined as the presence of $50 \%$ or more erythroid precursors and $20 \%$ or more blasts in the nonerythroid component. The pure erythroid leukemia subtype is composed of $80 \%$ or more immature erythroblasts. It accounts for less than 5\% of cases of acute myeloblastic leukemia. Usually occurs in patients 50 years of age or older but it can occur in children too (the incidence is rare). It is characterized by a prominent component of erythroblast. Erythroleukemia often come after Myelodysplasia, but it can also develop de novo. The prognosis of erythroleukemia is poor. The median survival is 3 months. Acute erythroleukemia should be distinguished from Myelodysplasia, refractory anemia with excess blasts, reactive erythroid hyperplasia following therapy administration with erythropoietin, megaloblastic anemia, acute myeloblastic megakaryocytic leukemia (LAM 7), lymphoma and Acute lymphoblastic leukemia.
Immunophenotyping on bone marrow aspirate shows glycophorin A, CD36+, CD71+. Erythroleukemia characterizes from hepatomegaly this is found and in our case. Myelodysplastic syndromes (MDS) are a group of biologically and clinically heterogeneous clonal disorders characterized by ineffective hematopoiesis and peripheral cytopenia due to high apoptosis and by variable tendency to evolve to bone marrow failure or acute myeloblastic leukemia. Commonly manifesting with macrocytosis and cytopenia due to impaired blood cell production.

\section{Conclusions:}

The diagnosis was Acute Erythroid Leukemia. The \% of myeloblasts in bone marrow was $>20 \%$ of non-erythroid cells. Erythroleukemia often come after Myelodysplasia, but it can also develop de novo. Immunophenotyping on bone marrow aspirate shows glycophorin A, CD36+, CD71+, CD 45+, CD 117+-, CD33+-, CD13+- but HLA-DR is negative and CD34-.

Erythroleukemia characterizes from hepatomegaly this is found and in our case. Differential diagnosis is based mainly in bone marrow aspiration, immunophenotyping (flow cytometry)

The prognosis of erythroleukemia is poor. The median survival is 3 months. The treatment is with chemotherapy cytarabines (ara C)

The regimen for induction therapy is the " $7+3$ " regimen: Cytarabine at $100 \mathrm{mg} / \mathrm{m} 2 / \mathrm{d}$ intravenously (IV) by continuous infusion on days 1-7 plus an anthracycline (idarubicin $12 \mathrm{mg} / \mathrm{m} 2$ or commonly used daunorubicin $45-60 \mathrm{mg} /$ $\mathrm{m} 2$ ) or anthracene Dione (mitoxantrone $12 \mathrm{mg} / \mathrm{m} 2$ ) (IV) push on days 1-3. [14, 15]

The regimen for consolidation therapy includes 2 options. The high-dose ara-C (HiDAC) regimen includes cytarabine at $3 \mathrm{~g} / \mathrm{m} 2 \mathrm{IV}$ q12h on days 1,3 , and 5 for 4 cycles. [16] The " $5+2$ " regimen includes cytarabine at $100 \mathrm{mg} / \mathrm{m} 2 / \mathrm{d}$ IV continuously infused on days $1-5$ plus daunorubicin at 45 $\mathrm{mg} / \mathrm{m} 2 \mathrm{IV}$ on days 1 and 2 for a total of 2 cycles. [17]

COI Statement: This paper has not been submitted in parallel. It has not been presented fully or partially at a meeting or podium or congress. It has not been published nor submitted for consideration beforehand.

All authors declare that there is no conflict of interest. This research received no specific grant from any funding agency in the public, commercial, or nonprofit sectors. There are no relevant or minor financial relationships from authors, their relatives or next of kin with external companies.

Disclosure: The authors declared no conflict of interest. No funding was received for this study.

Acknowledgement: 


\section{References}

1. Wintrobe's Clinical Haematology $14^{\text {th }}$ edition 76: pp 49355017

2. Oxford handbook of Clinical Haematology 4:120-131

3. Postgraduate Haematology $7^{\text {th }}$ edition

4. Clinical advances in Haematology and oncology. April 2010 vol.8 issue 4

5. Di Guglielmo G. Le Maltase Eritremiche Ed Eritroleucemiche. II Pensiero Scientifico. Haematologica. 1928; 9: 301347.

6. Arber DA, Orazi A. Hasserjan R et al.the 2016 revision to the WHO classification of myeloid neoplasms and acute leukemia Blood $2016 ; 127: 2391-2405$

7. Wei Wang, Sa A. Wang, L. Medeiros, Joseph D.Khoury American Journal of Haematology February 2017

8. Roggli VL, Saleem A. Erythroleukemia: a study of 15 cases and literature review. Cancer. 1982; 49: 101-108.

9. Bennett JM, Catovsky D, Daniel MT, et al. Proposed revised criteria for the classification of acute myeloid leukemia. A report of the French-American-British Cooperative Group. Ann Intern Med. 1985; 103: 620-625.

10. Swerdlow SH, Campo E, Harris NL, et al, eds. WHO Classification of Tumors of Hematopoietic and Lymphoid Tissues (IARC WHO Classification of Tumours). 4th ed. Lyon, France: WHO Press; 2008.

11. Goldberg SL, Noel P, Lumpp TR, Dewald G. The erythroid leukemias: a comparative study of erythroleukemia (FABM6) and Di Guglielmo disease. Am J Clin Oncol. 1998; 21: 42-47.

12. Wheatley K, Burnett AK, Goldstone AH, et al. A simple, robust, validated and highly predictive index for the determination of risk directed therapy in acute myeloid leukemia derived from the MRC AML10 trial. Br J Haematol. 1999;107: 69-79.

13. Davey FR, Abraham N, Brunetto VL, et al. Morphologic characteristics of erythroleukemia (acute myeloid leukemia; FAB-M6): a CALGB study. Am J Hematol. 1995; 49: 29-38. 6 Clinical Advances in Hematology \& Oncology Volume 8, Issue 4 April 2010

14. McHayleh W, Sehgal R, Redner RL, Raptis A, Agha M, Natale $\mathrm{J}$, et al. Mitoxantrone and etoposide in patients with newly diagnosed acute myeloid leukemia with persistent leukemia after a course of therapy with cytarabine and idarubicin. Leuk Lymphoma. 2009 Oct 8. [Medline].
15. Stoneking CJ, Mason MJ. Mg2 + modulation of the single-channel properties of $\mathrm{KCa} 3.1$ in human erythroleukemia cells. Pflugers Arch. 2013 Nov 6. [Medline].

16. Mayer RJ, Davis RB, Schiffer CA, et al. Intensive postremission chemotherapy in adults with acute myeloid leukemia. Cancer and Leukemia Group B. N Engl J Med. 1994 Oct 6. 331(14):896-903. [Medline].

17. Wiernik PH, Banks PL, Case DC Jr, et al. Cytarabine plus idarubicin or daunorubicin as induction and consolidation therapy for previously untreated adult patients with acute myeloid leukemia. Blood. 1992 Jan 15. 79(2):313-9. [Medline].

18. Kowal-Vern A, Mazzella FM, Cotelingam JD, et al. Diagnosis and characterization of acute erythroleukemia subsets by determining the percentages of myeloblasts and proerythroblasts in 69 cases. Am J Hematol. 2000; 65: 5-13.

19. Olopade OI, Thangavelu M, Larson RA, et al. Clinical, morphologic and cytogenetic characteristics of 26 patients with acute erythroblastic leukemia. Blood. 1992; 80: 2873-2882.

20. Mazzella F, Alvares C, Kowal-Vern A, Schumacher H. The acute erythroleukemias. Clin Lab Med. 2000; 20:119-137.

21. Kowal-Vern A, Cotelingam J, Schumacher HR. The prognostic significance of proerythroblasts in acute erythroleukemia. Am J Clin Pathol. 1992; 98: 34-40.

22. Southcott MJ, Tanner MJ, Anstee DJ. The expression of human blood group antigens during erythropoiesis in a cell culture system. Blood. 1999; 93: 4425-4435.

23. Garand R, Duchayne E, Blanchard D, et al. Minimally differentiated erythroleukemia (AML M6 'variant'): a rare subset of AML distinct from AML M6. Groupe Francais d Hematologie Cellulaire. Br J Haematol. 1995; 90: 868-875.

24. Jaffe ES, Harris NL, Stein H, Vardiman JW, eds. Pathology and Genetics: Tumours of Haematopoietic and Lymphoid Tissues (WHO Classification of Tumours). Lyon, France: IARC Press; 2001.

25. Atkinson J, Hrisinko MA, Weil SC. Erythroleukemia: a review of 15 cases meeting 1985 FAB criteria and survey of the literature. Blood Rev. 1992; 6: 204-214.

26. Park S, Picard F, Azgui Z, et al. Erythroleukemia: a comparison between the previous FAB approach and the WHO classification. Leuk Res. 2002; 26: 423-429. 